\section{A) Check for updates}

Cite this: Polym. Chem., 2019, 10 4322

\title{
Influence of ions to modulate hydrazone and oxime reaction kinetics to obtain dynamically cross-linked hyaluronic acid hydrogels $\uparrow$
}

\author{
Shujiang Wang, $\ddagger^{\mathrm{a}, \mathrm{b}}$ Ganesh N. Nawale, (D) $\ddagger^{\mathrm{b}}$ Oommen P. Oommen, (D) \\ Jöns Hilborn ${ }^{\mathrm{b}}$ and Oommen P. Varghese (iD) *b
}

\begin{abstract}
Dynamic covalent chemistry forming hydrazone and oxime linkages is attractive due to its simplicity, selectivity and compatibility under aqueous conditions. However, the low reaction rate at physiological $\mathrm{pH}$ hampers its use in biomedical applications. Herein, we present different monovalent and bivalent aqueous salt solutions as bio-friendly, non-toxic catalysts which can drive the hydrazone and oxime reactions with excellent efficacy at physiological $\mathrm{pH}$. Direct comparison of hydrazone and oxime reactions using a small molecule model, without any salt catalysis, indicated that oxime formation is 6 -times faster than hydrazone formation. Addition of different salts $\left(\mathrm{NaCl}, \mathrm{NaBr}, \mathrm{KCl}, \mathrm{LiCl}, \mathrm{LiClO}{ }_{4}, \mathrm{Na}_{2} \mathrm{SO}_{4}, \mathrm{MgCl}_{2}\right.$ and $\mathrm{CaCl}_{2}$ ) accelerated the pseudo-first-order reaction kinetics by $\sim 1.2-4.9$-fold for acylhydrazone formation and by $\sim 1.5-6.9$-fold for oxime formation, in a concentration-dependent manner. We further explored the potential of such catalysts to develop acylhydrazone and oxime cross-linked hyaluronic acid (HA) hydrogels with different physicochemical properties without changing the degree of chemical modification. Analogous to the small molecule model system, the addition of monovalent and divalent salts as catalysts significantly reduced the gelling time. The gelling time for the acylhydrazone cross-linked HAhydrogel (1.6 wt\%) could be reduced from $300 \mathrm{~min}$ to $1.2 \mathrm{~min}$ by adding $100 \mathrm{mM} \mathrm{CaCl}$, while that for the oxime cross-linked HA-hydrogel (1.2 wt\%) could be reduced from $68 \mathrm{~min}$ to $1.1 \mathrm{~min}$ by adding $50 \mathrm{mM}$ $\mathrm{CaCl}_{2}$. This difference in the gelling time also resulted in hydrogels with differential swelling properties as measured after $24 \mathrm{~h}$. Our results are the first to demonstrate the use of salts, for catalyzing hydrogel formation under physiologically relevant conditions.
\end{abstract}

Received 12th June 2019
Accepted 2nd July 2019

DOI: 10.1039/c9py00862d

rsc.li/polymers deliver living cells and sensitive biomolecules in vivo for biomedical applications. ${ }^{5}$ There are different methods to develop hydrogels including chemically modified polymers having reactive functional groups to obtain covalent cross-links, physical entanglement or electrostatic interactions between oppositely charged polymers or materials. ${ }^{6-9}$ Among these, dynamic covalent chemistry, such as hydrazone and oxime formation reactions, has gained much attention due to its simplicity, selectivity and efficiency and the requirement of mild reaction conditions. ${ }^{9-13}$ However, these conjugation strategies are associated with a low reaction rate at physiological $\mathrm{pH}^{14}{ }^{14}$ To overcome this problem, several synthetic catalysts have been developed to enhance the rates of hydrazone and oxime formation reactions. ${ }^{15-18}$ The most commonly used catalysts include aniline ${ }^{19}$ and aniline analogues ${ }^{18,20}$ which demonstrate good catalytic efficiency at acidic $\mathrm{pH}$ with aldehyde substrates, while the catalytic efficiency declines dramatically at physiological $\mathrm{pH}$, especially with the less reactive keto substrates. ${ }^{15}$ Other nucleophilic catalysts were also developed to improve coupling reactions at physiological $\mathrm{pH}^{15-17,20,21}$ The 


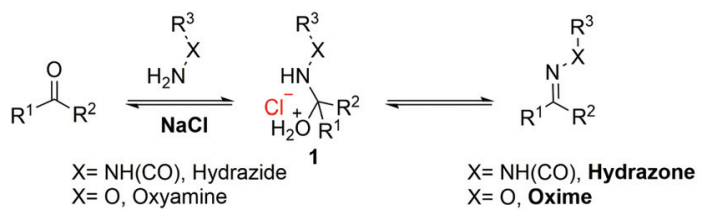

Scheme 1 Reaction scheme of the salt stabilized transition state for hydrazone and oxime formation.

reaction mechanism for hydrazone and oxime formation at neutral $\mathrm{pH}$ involves the formation of a charged intermediate $\mathbf{1}$, followed by a dehydration step of the intermediate $\mathbf{1}$ which is the rate-limiting step (Scheme 1).

We have recently demonstrated that carboxylates can promote the protonation of the hydroxyl oxygen atom in $\mathbf{1}$ at neutral $\mathrm{pH}$ by forming a cyclic intermediate. ${ }^{22}$ We also discovered that simple salts such as sodium chloride $(\mathrm{NaCl})$ could accelerate oxime formation at neutral $\mathrm{pH}$ with both the aldehyde and less reactive keto substrates by stabilizing the rate limiting transition state, thereby promoting the dehydration step. ${ }^{23}$ It is important to note that so far the salt based catalytic system has only been applied to oxime-based conjugation reactions; however, the effect of salts on the formation of hydrazone at neutral $\mathrm{pH}$ remains unclear. We hereby report the effects of different salts on the reaction kinetics of acylhydrazone and oxime formation reactions. We also demonstrate the influence of salts on the cross-linking efficiency of biomacromolecules to form hydrogels. We explored the gelling kinetics in the presence of different salts, without changing the degree of chemical modification on the polymers.

\section{Results and discussion}

To evaluate the effects of various salts on the reaction kinetics of acylhydrazone and oxime formation reactions, we first performed model reactions with a small molecule model, namely, 4-nitrobenzaldehyde as an electrophile and adipic dihydrazide or (aminooxy)methane as a nucleophile (Scheme S1, ESI $\dagger$ ). The pseudo-first-order reaction rates were analyzed in $10 \mathrm{mM}$ phosphate buffer (PB, pH 7.4) containing 10\% DMF by employing different salt concentrations (Fig. 1). Interestingly, an aqueous solution containing $\mathrm{NaCl}$ indeed accelerated both the acylhydrazone and oxime formation reactions in a salt concentration-dependent manner, which corroborates with our recent observation of oxime reaction catalysis with saline. ${ }^{23}$

In the case of acylhydrazone, when $50 \mathrm{mM} \mathrm{NaCl}$ was used as a catalyst, the reaction rates were increased by $\sim 1.2$-fold as compared to that of the uncatalyzed reaction (Fig. 2a). Gratifyingly, when the $\mathrm{NaCl}$ concentration was further increased to $100 \mathrm{mM}$ and $1 \mathrm{M}$, we observed an $\sim 1.4$-fold and $\sim 3$.9-fold increase in the reaction rate, compared to that of the uncatalyzed reaction (Fig. 2a). When similar salt concentrations (50 mM, $100 \mathrm{mM}$ and $1 \mathrm{M} \mathrm{NaCl}$ ) were used in the oxime formation reaction, we observed $\sim 1.5$-fold, $\sim 1$.6-fold and $\sim 5$.8-fold increments in the rate as compared to those of
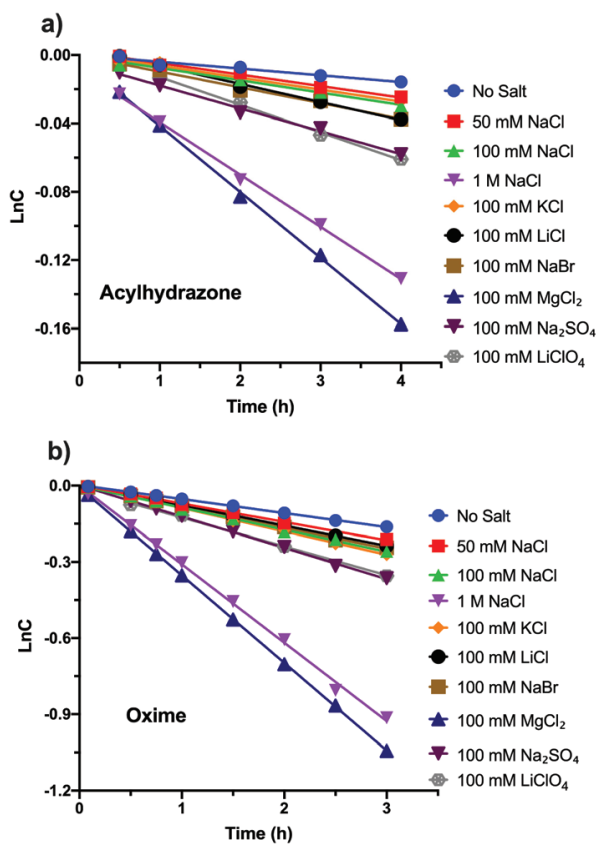

Fig. 1 Representative examples of reaction kinetics with $64 \mu \mathrm{M}$ nitrobenzaldehyde and (a) $1 \mathrm{mM}$ adipic dihydrazide and (b) $2 \mathrm{mM}$ (aminooxy) methane in $10 \mathrm{mM}$ phosphate buffer (PB, $7.5 \mathrm{mM} \mathrm{Na}_{2} \mathrm{HPO}_{4}$ and $2.5 \mathrm{mM}$ of $\mathrm{NaH}_{2} \mathrm{PO}_{4}$ ) containing $10 \%$ DMF. Reactions were performed at $23^{\circ} \mathrm{C}$.

the uncatalyzed reactions (Fig. 2b). Though the reaction kinetics indicated a similar enhancement of reaction rates for both acylhydrazone and oxime reactions, it should be noted that the oxime formation reaction was $\sim 6.2$-times faster than the acylhydrazone formation reaction without any salt $\left(k_{\mathrm{obs}}=0.054\right.$ for oxime and $k_{\text {obs }}=0.0087$ for acylhydrazone).

Since both the cation and anion participate in the stabilization of the rate-limiting step, overcoming the $\alpha$-effect induced by nucleophilic reagents ${ }^{23,24}$ such as hydrazide and aminooxy groups, we investigated the effect of other ions on the reaction rate. All the monovalent salts tested ( $\mathrm{NaCl}, \mathrm{NaBr}, \mathrm{KCl}, \mathrm{LiCl}$, and $\mathrm{LiClO}_{4}$ ) indicated similar levels of increase in the reaction rate ( 1.4-1.8-fold) with both hydrazide and aminooxy substrates when the salt concentration was kept at $100 \mathrm{mM}$. Interestingly, when $100 \mathrm{mM} \mathrm{Na} \mathrm{SO}_{4}$ and $\mathrm{MgCl}_{2}$ were used in the reaction, a $\sim 2$.1-fold and $\sim 4$.9-fold increase in the reaction rate was observed, respectively, for acylhydrazone formation (Fig. 2a). A similar pattern of rate increase (2.3-fold and $\sim 7$ fold) was observed for oxime formation using the same catalysts (Fig. 2b). We also attempted to perform experiments with $\mathrm{CaCl}_{2}$ as a catalyst; however, at a $100 \mathrm{mM}$ concentration of $\mathrm{CaCl}_{2}$, we observed precipitation of the salt. Taken together, these results indicate that different ions in the reaction mixture catalyse the oxime and acylhydrazone formation reactions at physiological $\mathrm{pH}$. We believe that this effect is due to the increased ionic strength in the reaction medium which increases the local concentration of the organic molecules ('salting-out effect') and a decrease in the energy of the transition state, similar to our previous observation. ${ }^{23}$ In order to 

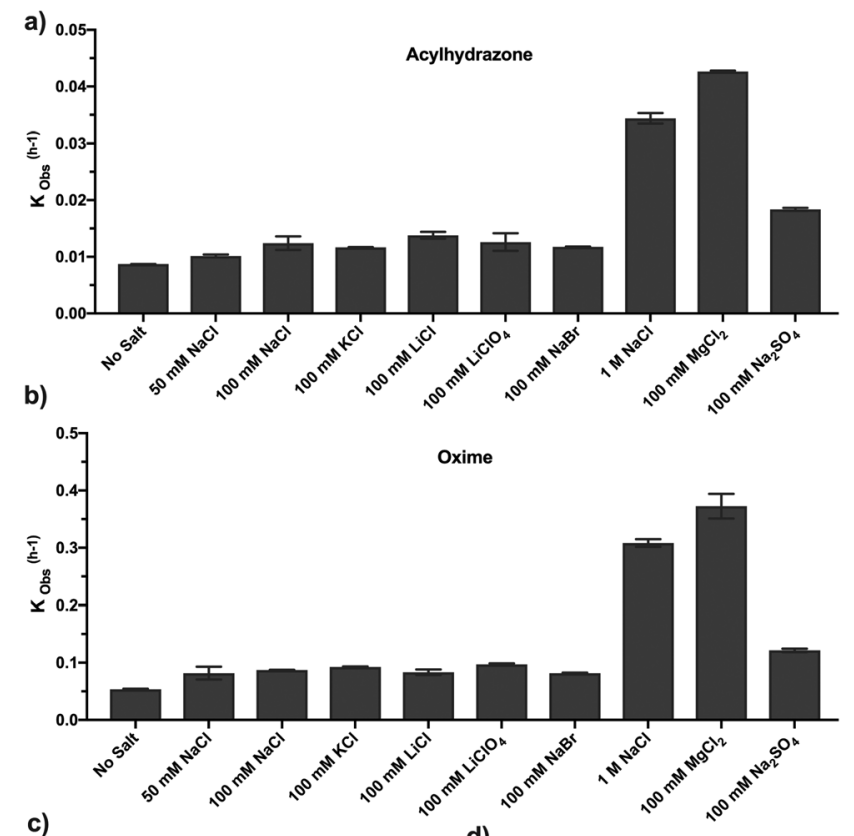

c)

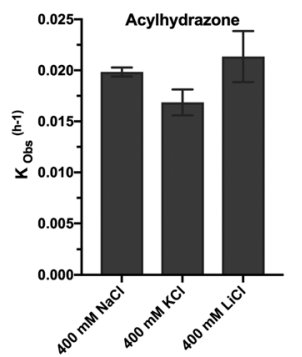

d)

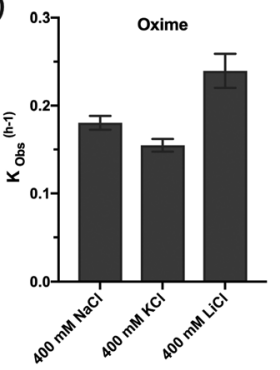

Fig. 2 Comparative pseudo-first-order reaction kinetics of salt-catalyzed acylhydrazone and oxime formation as determined by UV-Vis spectrophotometry. Reactions were performed using $64 \mu \mathrm{M}$ 4-nitrobenzaldehyde and (a) $1 \mathrm{mM}$ adipic dihydrazide or (b) $2 \mathrm{mM}$ (aminooxy) methane in $10 \mathrm{mM}$ phosphate buffer (PB, $7.5 \mathrm{mM} \mathrm{Na}_{2} \mathrm{HPO}_{4}$ and $2.5 \mathrm{mM}$ $\mathrm{NaH}_{2} \mathrm{PO}_{4}$ ) containing 10\% DMF. The salt out effect on the reaction rates of (c) acylhydrazone and (d) oxime formation evaluated with salts. Reactions were performed at $23^{\circ} \mathrm{C}$.

evaluate the salt effect, we performed reactions with a salt known to have a salt-out ( $\mathrm{LiCl})$ or salt-in $(\mathrm{KCl})$ effect based on the Hofmeister series with a higher salt concentration (400 mM). ${ }^{25}$ These experiments indicated that for both the hydrazone and oxime-formation reactions, $\mathrm{LiCl}$ accelerated the reaction rate, suggesting a salt-out effect, whereas $\mathrm{KCl}$ reduced the rate as compared to the $\mathrm{NaCl}$ catalyzed reaction (Fig. 2c and d). In order to determine whether our results are not due to an 'indirect' field effect, we compared the reaction rates using $\mathrm{LiCl}$ and $\mathrm{LiClO}_{4}$ having different anions. These experiments indicated a similar increase in the reaction rate, suggesting that the observed reaction rate is not due to the field effect but due to the salt-out effect (Fig. S1a and S1b in the $\left.\operatorname{ESI}_{\dagger}\right)$. It is noteworthy that the rate of the salt catalyzed reaction could be further enhanced by performing such reactions at a higher temperature (Fig. S1c in the ESI $\dagger$ ).

To exemplify the utility of these catalysts for bioconjugation, we explored the effects of salts to catalyze hydrazone and oxime cross-linking reactions to prepare hydrogels. For this purpose, we chemically modified hyaluronic acid (HA), a natural extracellular matrix component, with aldehyde and hydrazide/aminooxy modifications. HA is known to play a significant role in cell proliferation and migration ${ }^{26}$ and in maintaining the stem cell niche within our body. ${ }^{27}$ Therefore hydrogels using HA components have been extensively used for several biomedical applications, such as cell delivery, ${ }^{28}$ and drug delivery ${ }^{29}$ and in the field of regenerative medicine. ${ }^{30} \mathrm{We}$ have previously developed a hydrazone-cross-linked HA hydrogel $^{29}$ and used it to deliver recombinant human bone morphogenetic protein-2 (rhBMP-2) to regenerate bone in vivo. ${ }^{8,31} \mathrm{We}$ have also utilized such materials to deliver small molecule drugs $^{32}$ and large nucleic acid drugs $\mathrm{s}^{28,33,34}$ and for tuning the differential release of proteins. ${ }^{35}$ One of the key aspects of hydrogel preparation is the reaction kinetics of gel formation. We have recently shown that by modulating the thiol $\mathrm{p} K_{\mathrm{a}}$, in a thiol-functionalized HA, it is possible to control the crosslinking density and hydrogel swelling properties of the disulfide cross-linked HA hydrogel. ${ }^{36}$ This prompted us to investigate the effect of gelling kinetics on the properties of hydrazone and oxime cross-linked hydrogels.

To develop hydrazone cross-linked HA hydrogels, we first prepared aldehyde and hydrazide derivatives of HA using our previously optimised method..$^{29,37}$ It is noteworthy that the hydrazide unit contained a urea-type of linkage which allowed the delocalisation of charges, resulting in improved stability of the hydrazone linkages. The degree of modification was observed to be $6 \%$ for hydrazide modification and $12 \%$ for aldehyde modification. To develop oxime cross-linked HAhydrogels, we synthesized a novel aminooxy HA employing a carbodiimide coupling reaction with $\mathrm{HA}$ at $\mathrm{pH} 4.7$ with a 10-fold excess of the diaminooxy linker (with respect to the carbodiimide, Scheme S3, ESI $\dagger$ ) with a dual modification. ${ }^{37}$ The diaminooxy linker was prepared following a reported method (Scheme S2, ESI $\dagger$ ). ${ }^{38}$ The aminooxy modified HA derivative was purified by dialysis and characterized by ${ }^{1} \mathrm{H}$ NMR analysis (Fig. S1, ESI $\dagger$ ). The degree of aminooxy substitution was determined by UV-vis spectrophotometry by following a modified trinitrobenzene sulfonic acid (TNBS) assay. ${ }^{39}$ These experiments indicated a $7 \%$ modification of HA-aminooxy residues with respect to the disaccharide repeat unit. The chemically modified polymers were used to prepare HA hydrogels in PB (10 mM, pH 7.4) with different concentrations of salts by mixing an equal volume ratio (1:1) of HA-hydrazide/aminooxy and HA-aldehyde derivatives at $16 \mathrm{mg} \mathrm{mL}^{-1}$ concentrations (Scheme S4, ESI $\dagger$ ) to obtain gels with $1.6 \mathrm{wt} \%$. The influence of the aqueous salt solution on the cross-linking reaction kinetics was determined by rheological measurements employing oscillatory time sweeps on the reaction mixture at a $1 \mathrm{~Hz}$ frequency and a controlled gap distance of $1 \mathrm{~mm}$. The storage modulus $\left(G^{\prime}\right)$ and loss modulus $\left(G^{\prime \prime}\right)$ were monitored against time to determine the gel point (the time when $G^{\prime}=G^{\prime \prime}$ ).

The acylhydrazone cross-linked HA hydrogels exhibited a slower reaction rate with a gelation time of $\sim 5 \mathrm{~h}$ under uncatalyzed reaction conditions (Fig. $3 \mathrm{a}$ and $4 \mathrm{a}$ ). Interestingly, the 
a)

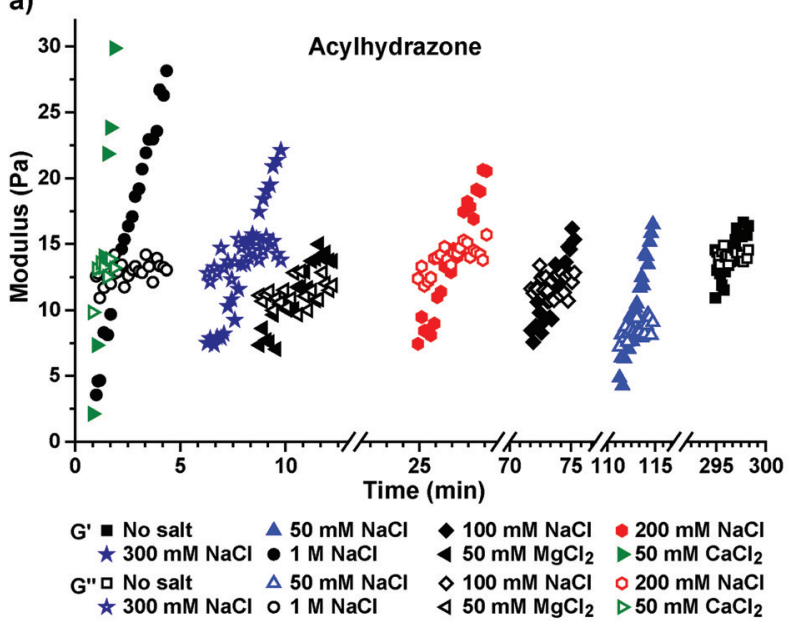

b)

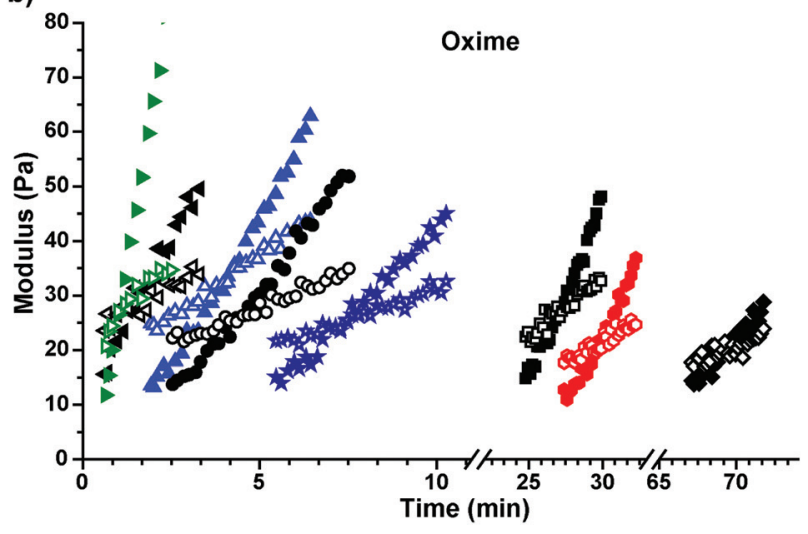

G' No salt-H $\quad \Delta 50 \mathrm{mM} \mathrm{NaCl}-\mathrm{H} \diamond$ No salt-L $\quad 50 \mathrm{mM} \mathrm{NaCl}-\mathrm{L}$ $\star 100 \mathrm{mM} \mathrm{NaCl}-\mathrm{L} \bullet 150 \mathrm{mM} \mathrm{NaCl}-\mathrm{L} \ 50 \mathrm{mM} \mathrm{MgCl} 2-\mathrm{L} \gg 50 \mathrm{mM} \mathrm{CaCl} 2-\mathrm{L}$ G" $\square$ No salt-H $\quad \triangle 50 \mathrm{mM} \mathrm{NaCl}-\mathrm{H} \diamond$ No salt-L $\quad 050 \mathrm{mM} \mathrm{NaCl}-\mathrm{L}$

$\star 100 \mathrm{mM} \mathrm{NaCl}-\mathrm{L} \bigcirc 150 \mathrm{mM} \mathrm{NaCl}-\mathrm{L} \triangleleft 50 \mathrm{mM} \mathrm{MgCl}_{2}-\mathrm{L} \triangleright 50 \mathrm{mM} \mathrm{CaCl} 2-\mathrm{L}$

Fig. 3 Rheological analysis of (a) acylhydrazone cross-linked HAhydrogel with an HA concentration of $1.6 \mathrm{wt} \%$ and (b) oxime crosslinked HA-hydrogel with a high (H) HA concentration of $1.6 \mathrm{wt} \%$ or a low (L) HA concentration of 1.2 wt\%.

gelation time decreased to $\sim 2 \mathrm{~h}$ in the presence of $50 \mathrm{mM}$ $\mathrm{NaCl}$, which further decreased to $\sim 71.6 \mathrm{~min}$ and $\sim 26.2 \mathrm{~min}$ with $100 \mathrm{mM}$ and $200 \mathrm{mM} \mathrm{NaCl}$, respectively. When the $\mathrm{NaCl}$ concentration was further increased to $300 \mathrm{mM}$ and $1 \mathrm{M}$, the gelation time was dramatically decreased to $\sim 8.3 \mathrm{~min}$ and $\sim 2.3 \mathrm{~min}$, respectively (Fig. 3a and 4a).

When $100 \mathrm{mM} \mathrm{MgCl}$ and $100 \mathrm{mM} \mathrm{CaCl}_{2}$ were used as catalysts, the gelation time reduced to $\sim 2.7 \mathrm{~min}$ and $\sim 1.2 \mathrm{~min}$, respectively, for the acylhydrazone-cross-linked hydrogel (Fig. 3 and 4$)$. In the oxime-cross-linked hydrogel formation reaction (1.2 wt\%), $50 \mathrm{mM} \mathrm{MgCl}$ and $50 \mathrm{mM} \mathrm{CaCl}{ }_{2}$ reduced the gelation time to $\sim 1.5 \mathrm{~min}$ and $\sim 1.1-\mathrm{min}$, respectively. We then proceeded to evaluate the hydrogel rheological properties after $48 \mathrm{~h}$ of mixing the gel components. For this purpose, we prepared HA hydrogels with different salts as discussed above. After $24 \mathrm{~h}$, these hydrogels were suspended in $10 \mathrm{mM}$ PBS for an additional $24 \mathrm{~h}$ to remove excess salts, and then the rigidity a)

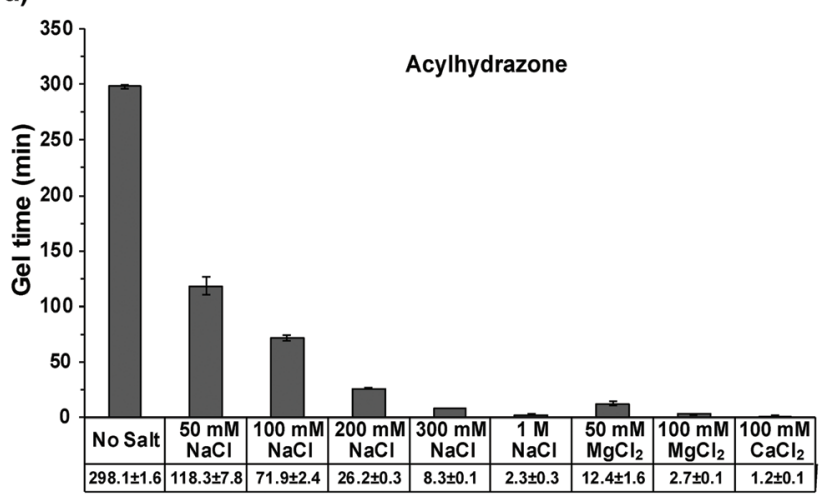

b)

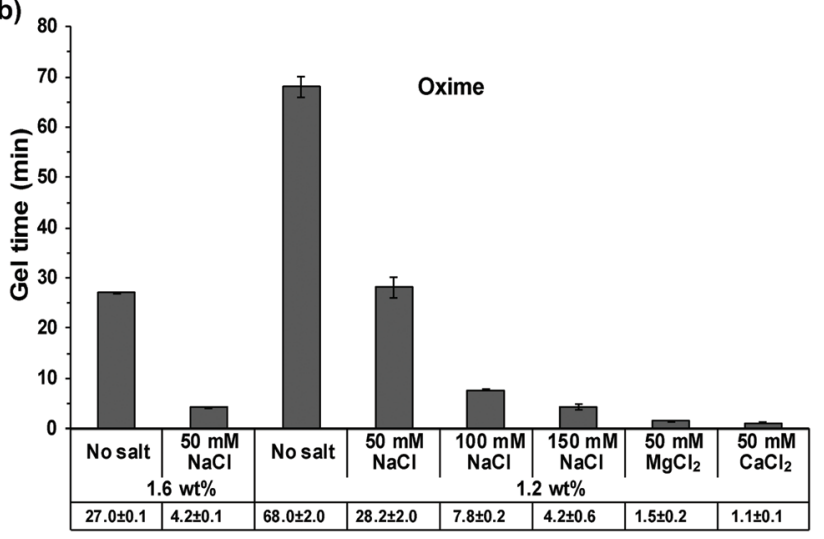

Fig. 4 The gel time of (a) acylhydrazone cross-linked HA-hydrogel with an HA concentration of $1.6 \mathrm{wt} \%$ and (b) oxime cross-linked HA-hydrogel with an HA concentration of $1.6 \mathrm{wt} \%$ or $1.2 \mathrm{wt} \%$.

of the hydrogels was analyzed by performing rheological measurements using oscillatory frequency sweep. The observed rheological data (Table 1) therefore represent a relative measure of the cross-linking densities that were obtained using different salt concentrations during the cross-linking reaction.

As shown in Table 1, for acylhydrazone cross-linked hydrogels, the rigidity increased with an increase in the salt concentration. For oxime hydrogels, however, the addition of $50 \mathrm{mM}$ $\mathrm{NaCl}$ increased the storage modulus but not when $50 \mathrm{mM}$ $\mathrm{MgCl}_{2}$ was used. We believe this is due to the extremely high reaction rate when $\mathrm{MgCl}_{2}$ was used as a catalyst resulting in inhomogeneous hydrogel formation due to inefficient mixing

Table 1 Properties of acylhydrazone and oxime cross-linked hydrogels after $24 \mathrm{~h}$ swelling in PBS

\begin{tabular}{|c|c|c|c|}
\hline Hydrogel & Salt & $G^{\prime}(\mathrm{Pa})$ & $G^{\prime \prime}(\mathrm{Pa})$ \\
\hline \multirow[t]{4}{*}{ Acylhydrazone } & No salt & $416.5 \pm 8.2$ & $13.8 \pm 1.1$ \\
\hline & 50 mM NaCl & $435.8 \pm 13.0$ & $13.7 \pm 2.1$ \\
\hline & $50 \mathrm{mM} \mathrm{MgCl}{ }_{2}$ & $1145.0 \pm 25.1$ & $17.6 \pm 0.2$ \\
\hline & 150 mM NaCl & $1240.0 \pm 18.0$ & $17.7 \pm 0.8$ \\
\hline \multirow[t]{3}{*}{ Oxime } & No salt & $2101.5 \pm 17.5$ & $34.2 \pm 6.4$ \\
\hline & 50 mM NaCl & $3171.0 \pm 156.0$ & $39.6 \pm 5.4$ \\
\hline & $50 \mathrm{mM} \mathrm{MgCl}_{2}$ & $2067.0 \pm 13.0$ & $22.2 \pm 5.6$ \\
\hline
\end{tabular}




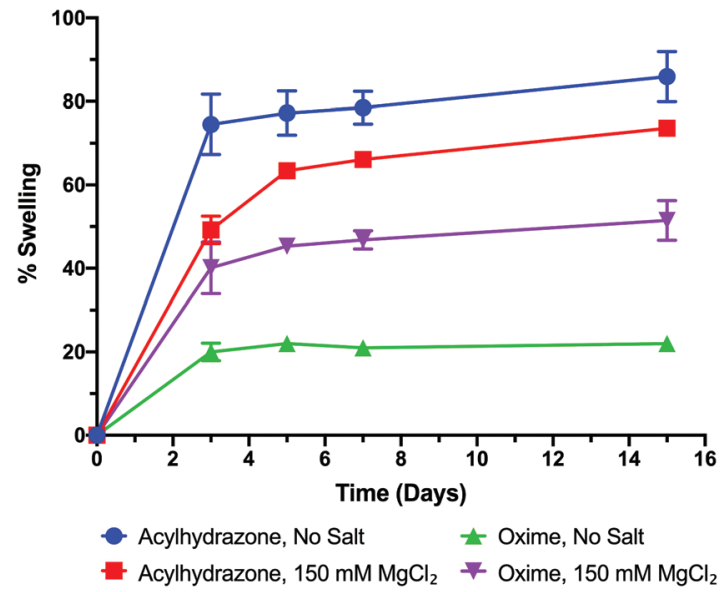

Fig. 5 The effect of reaction kinetics on the swelling of acylhydrazone and oxime cross-linked HA-hydrogels. HA solid content is $1.6 \mathrm{wt} \%$.

of the gel precursors. These results indicate that optimal reaction kinetics for oxime formation is needed for appropriate gel formation. Too fast reactions will not permit mixing to allow reactive functional groups to meet each other, while slow reactions would require a longer time until complete conversion.

In order to validate the influence of hydrogel gelling kinetics on the swelling behaviour of the biomaterials, we performed experiments with $1.6 \mathrm{wt} \%$ HA-hydrogels having acylhydrazone and oxime cross-linkages. As anticipated, without any salts, the acylhydrazone cross-linked hydrogels exhibited excessive swelling ( $\sim 75 \%)$ within three days while the oxime cross-linked gels demonstrated only $\sim 20 \%$ swelling (Fig. 5).

Addition of $\mathrm{MgCl}_{2}$, which is expected to reduce the reaction time significantly, reduced the swelling behaviour of the acylhydrazone cross-linked materials ( $50 \%$ in three days). This result corroborates with the increase in the storage modulus as a result of an increase in the gelling kinetics. In the case of the oxime reaction, on the other hand, we observed an increase in swelling ( $\sim 40 \%$ in three days) upon the addition of $\mathrm{MgCl}_{2}$ (Fig. 5). We believe that this unusual behavior with $\mathrm{MgCl}_{2}$ is due to the limited possibility to achieve homogeneous mixing of the gel components due to the too high reaction rates and too short gelation time. It is interesting to note that the initial swelling ratio after the first five days was maintained even after 15 days of incubation, indicating that the dynamic crosslinked gels once formed remain stable at physiological $\mathrm{pH}$ in the presence of salts in the buffer (Fig. 5).

\section{Conclusions}

In summary, we present a simple and efficient strategy to modulate hydrazone and oxime formation kinetics at physiological $\mathrm{pH}$ by utilizing simple salts as catalysts. Increasing the $\mathrm{NaCl}$ concentration or using divalent salts such as $\mathrm{MgCl}_{2}$ or $\mathrm{CaCl}_{2}$ can significantly accelerate the reaction rates for such reactions. The increase in the reaction rates was demonstrated in both small molecules and multifunctional biomacromolecules and utilized for designing acylhydrazone and oxime-based hydrogels under physiologically relevant conditions. This simple strategy to modulate hydrazone and oxime reaction kinetics will provide a great advantage for developing biomaterials or for bioconjugation applications.

\section{Conflicts of interest}

There are no conflicts to declare.

\section{Acknowledgements}

We acknowledge financial support from the Swedish Strategic Research 'StemTherapy' (Dnr 2009-1035) and the Swedish Foundation for Strategic Research (SSF, SBE13-0028).

\section{Notes and references}

1 A. S. Hoffman, Adv. Drug Delivery Rev., 2012, 64, 18-23.

2 J. Kopecek, Biomaterials, 2007, 28, 5185-5192.

3 D. Seliktar, Science, 2012, 336, 1124-1128.

4 M. W. Tibbitt and K. S. Anseth, Biotechnol. Bioeng., 2009, 103, 655-663.

5 J. A. Burdick and G. D. Prestwich, Adv. Mater., 2011, 23, H41-H56.

6 A. Sigen, Q. Xu, P. McMichael, Y. Gao, X. Li, X. Wang, U. Greiser, D. Zhou and W. Wang, Chem. Commun., 2018, 54, 1081-1084.

7 T. R. Hoare and D. S. Kohane, Polymer, 2008, 49, 19932007.

8 H. J. Yan, T. Casalini, G. Hulsart-Billström, S. Wang, O. P. Oommen, M. Salvalaglio, S. Larsson, J. Hilborn and O. P. Varghese, Biomaterials, 2018, 161, 190-202.

9 A. E. G. Baker, R. Y. Tam and M. S. Shoichet, Biomacromolecules, 2017, 18, 4373-4384.

10 O. P. Oommen, S. J. Wang, M. Kisiel, M. Sloff, J. Hilborn and O. P. Varghese, Adv. Funct. Mater., 2013, 23, 1273-1280.

11 K. Jeet and R. T. Raines, Angew. Chem., Int. Ed., 2008, 47, 7523-7526.

12 M. Rashidian, M. M. Mahmoodi, R. Shah, J. K. Dozier, C. R. Wagner and M. D. Distefano, Bioconjugate Chem., 2013, 24, 333-342.

13 G. N. Grover, J. Lam, T. H. Nguyen, T. Segura and H. D. Maynard, Biomacromolecules, 2012, 13, 3013-3017.

14 E. H. Cordes and W. P. Jencks, J. Am. Chem. Soc., 1962, 84, 832-837.

15 D. K. Kölmel and E. T. Kool, Chem. Rev., 2017, 117, 1035810376.

16 D. Larsen, A. M. Kietrys, S. A. Clark, H. S. Park, A. Ekebergh and E. T. Kool, Chem. Sci., 2018, 9, 5252-5259.

17 M. Rashidian, M. M. Mahmoodi, R. Shah, J. K. Dozier, C. R. Wagner and M. D. Distefano, Bioconjugate Chem., 2013, 24, 333-342. 
18 M. Wendeler, L. Grinberg, X. Wang, P. E. Dawson and M. Baca, Bioconjugate Chem., 2014, 25, 93-101.

19 A. Dirksen, S. Dirksen, T. M. Hackeng and P. E. Dawson, J. Am. Chem. Soc., 2006, 128, 15602-15603.

20 P. Crisalli and E. T. Kool, J. Org. Chem., 2013, 78, 1184-1189.

21 D. Larsen, M. Pittelkow, S. Karmakar and E. T. Kool, Org. Lett., 2015, 17, 274-277.

22 S. Wang, D. Gurav, O. P. Oommen and O. P. Varghese, Chem. - Eur. J., 2015, 21, 5980-5985.

23 S. Wang, G. N. Nawale, S. Kadekar, O. P. Oommen, N. K. Jena, S. Chakraborty, J. Hilborn and O. P. Varghese, Sci. Rep., 2018, 8, 2193.

24 E. G. Sander and W. P. Jencks, J. Am. Chem. Soc., 1968, 90(22), 6154-6162.

25 V. Mazzini and V. S. J. Craig, Chem. Sci., 2017, 8, 7052-7065.

26 T. Murakami, S. Otsuki, Y. Okamoto, K. Nakagawa, H. Wakama, N. Okuno and M. Neo, Connect. Tissue Res., 2018, 1-11, DOI: 10.1080/03008207.2018.1465053.

27 M. A. Solis, Y.-H. Chen, T. Y. Wong, V. Z. Bittencourt, Y.-C. Lin and L. L. H. Huang, Biochem. Res. Int., 2012, 2012, 346972-346972.

28 M. Paidikondala, G. N. Nawale and O. P. Varghese, Biomacromolecules, 2019, 20, 1317-1324.

29 O. P. Oommen, S. Wang, M. Kisiel, M. Sloff, J. Hilborn and O. P. Varghese, Adv. Funct. Mater., 2013, 23, 1273-1280.
30 J. Patterson, M. M. Martino and J. A. Hubbell, Mater. Today, 2010, 13, 14-22.

31 M. Kisiel, M. Ventura, O. P. Oommen, A. George, X. F. Walboomers, J. Hilborn and O. P. Varghese, J. Controlled Release, 2012, 162, 646-653.

32 O. P. Oommen, J. Garousi, M. Sloff and O. P. Varghese, Macromol. Biosci., 2014, 14, 327-333.

33 H. Yan, O. P. Oommen, D. Yu, J. Hilborn, H. Qian and O. P. Varghese, Adv. Funct. Mater., 2015, 25, 3907-3915.

34 M. Paidikondala, V. K. Rangasami, G. N. Nawale, T. Casalini, G. Perale, S. Kadekar, G. Mohanty, T. Salminen, O. P. Oommen and O. P. Varghese, Angew. Chem., Int. Ed., 2019, 58, 2815-2819.

35 S. Wang, O. P. Oommen, H. Yan and O. P. Varghese, Biomacromolecules, 2013, 14, 2427-2432.

36 D. Bermejo-Velasco, A. Azémar, O. P. Oommen, J. Hilborn and O. P. Varghese, Biomacromolecules, 2019, 20(3), 14121420.

37 O. P. Varghese, M. Kisiel, E. Martínez-Sanz, D. A. Ossipov and J. Hilborn, Macromol. Rapid Commun., 2010, 31, 11751180.

38 M. Wendeler, L. Grinberg, X. Wang, P. E. Dawson and M. Baca, Bioconjugate Chem., 2014, 25, 93-101.

39 W. A. Bubnis and C. M. Ofner 3rd, Anal. Biochem., 1992, 207, 129-133. 